\title{
LA FUNCIÓN DE VIRGILIO EN LA COMEDIA DE DANTE
}

\section{Julio Picasso Muñoz}

$\mathrm{E}$ 1 objetivo de este artículo es ampliar y aclarar más la doctrina que expuse en Matelda: alegoría y enigma, artículo publicado en 19841985 en el Boletín del Instituto Riva-Agüero (N.o 13). Allí traté de probar que el plan completo doctrinal de la Comedia de Dante, explanado con toda claridad en la Epistola XIII a Cangrande Della Scala, es el desarrollo de la teoría de las vidas activa y contemplativa. Para ello, Dante utilizó a cuatro personajes que las alegorizaban: Virgilio y Matelda, para la vida activa; Beatriz y san Bernardo, para la contemplativa. El artículo se centró en Matelda, que es la alegoría más elaborada y, a la vez, el mayor enigma de toda la Comedia. Ahora nos centraremos en Virgilio.

En retórica clásica, el ornatus elocutionis requiere muchas y variadas figuras, y una de las clases de las figuras de la oración (frente al asunto) (Lausberg 1966) se basa en la inmutatio o trasmutación de los pensamientos.

* Es conocido por sus artículos y traducciones de Petronio (Satiricón, Madrid: Cátedra, 1984), los Cinco opúsculos teológicos de Boecio (Lima: Fondo editorial de la PUCP) y la Eneida, de Virgilio (Lima: Fondo Editorial UCSS). Es un especialista en lenguas clásicas — latín, griego y hebreo — formado en la Universidad de la Sorbona en París. Es miembro de la Dante Society of America (Universidad de Harvard), del Instituto Riva-Agüero, de la Sociedad Hispánica de Estudios Neogriegos (Granada, España) y miembro fundador de la Sociedad Peruana de Estudios Clásicos. Actualmente es docente investigador y profesor de Latín de la Universidad Católica Sedes Sapientiae. 
A ella pertenecen los famosos cinco tropos de pensamiento: ironía, énfasis, sinécdoque, hipérbole y alegoría.

Expliquémoslas con ejemplos virgilianos: para la ironía, las palabras de Dido: Los dioses tienen trabajo, su quietud ya tiene en qué ocuparse (En., IV, 379). Para el énfasis: Se deslizan por una cuerda colgada (En., II, 262), para indicar la gran altura del caballo de Troya. Para la sinécdoque: Era la hora en que el sopor primero, don divino, viene a los tristes mortales $y$, placentero, se insinúa en ellos (En., II, 268), para designar el atardecer. Para la hipérbole: Se creyera ver flotar a las Cíclades arrancadas o que unos altos montes corren a estrellarse contra otros (En., VIII, 691-692), para designar un combate naval. Para la alegoría, estudiar al personaje Menalcas (Buc., IX, 7-10), que alegoriza al propio Virgilio. ${ }^{1}$

Se puede, pues, expresar un pensamiento, propuesto en serio, por medio de otro pensamiento. La uoluntas semántica tiene así dos planos: el plano serio, que constituye la intención del autor, la verdadera uoluntas (Virgilio, en el último ejemplo), y el plano de juego en el que se mienta en primer lugar otra uoluntas (Menalcas, con algún parecido en su vida que indica a Virgilio), que a su vez sirve únicamente como medio expresivo de la uoluntas seria. Las figuras por trasmutación son, pues, tropos de pensamiento, no de simples ideas o palabras. La alegoría es al pensamiento lo que la metáfora es a la palabra aislada. La alegoría y la metáfora desarrollan una fuerza expresiva gracias a su contenido afectivo.

El plano de juego (PJ) contiene lo que se llama el sentido literal o histórico de la alegoría. En cambio, el plano serio (PS) señala el sentido real, llamado también «espiritual» o, por así decir, «alegórico de la alegoría». No hay que olvidar que ambos planos constituyen una sola alegoría: PJ $\leftrightarrow$ PS.

Lo corriente es partir de un PJ fácil de entender — Dante lo llama «bella mentira»— para llegar al PS. Una alegoría que encierra oscuridad

1 La UCSS ha publicado la traducción de todas las obras de Virgilio en Bucólicas y Geórgicas (2004) y Eneida (2007). 
recibe el nombre de enigma, al que a veces Dante recurre. Aconsejo leer el cap. IX del libro XV del De Trinitate de san Agustín, donde se trata de la alegoría y del enigma y donde se halla la célebre frase: Hoc est grandius aenigma, ut non uideamus quod non uidere non possumus ('He aquí el gran enigma: no ver lo que no podemos menos que ver').

En este punto debemos decir que la humanidad empezó a leer alegóricamente antes de que los autores fabricaran alegorías. El causante de este fenómeno fue sin duda Platón, quien, tras criticar duramente la literatura mítica corriente por inmoral y falsa, llegó a desterrar a Homero de su República. Frente a la imposibilidad de cumplir este deseo platónico, los griegos reaccionaron de dos maneras: una, la de los moralizantes, se contentó con prevenir a sus alumnos sobre la «inmoralidad» de ciertos versos; otra, la de los alegoristas, decretaban que "eso» significaba otra cosa. Y así empezaron a leerse las obras menos alegorizadas que existen, que son las dos obras homéricas.

Los judíos, con Filón a la cabeza, empezaron también a ver alegorías en cada renglón de la Biblia. Más incluso, varios libros de la Biblia, en especial los apocalípticos y proféticos, elaboraron conscientemente complicadas alegorías, como la gigantesca estatua soñada por Nabucodonosor (Dan II, 31-33), trasfigurada por Dante en el Veglio di Creta (If., XIV, 94-120).

Los Evangelios continuaron con la interpretación alegórica del Antiguo Testamento, y el Apocalipsis fue elaborado en base de alegorías y enigmas. San Pablo mismo expresa que lo de los dos hijos de Abrahán está dicho «alegóricamente» (Gal 4, 24), pues designan a los dos Testamentos, aunque el término que prevaleció en el Nuevo Testamento, en vez de alegoría, fue «tipo». Jesucristo tampoco encontró inconveniente en decir que el caso de Jonás y el de la serpiente de bronce lo prefiguraban a Él. Los cristianos, pues, hacemos nuestro el viejo adagio de san Agustín: Nouum in Vetere latet et in Nouo Vetus patet (Hept., 2, 73).

Debemos ahora subrayar que el PJ puede envolver un personaje «histórico» (real o mitológico), un suceso, un hecho del pasado o, si no, algo completamente imaginado (persona, estatua, monstruo, suceso...) 
fácil de ser interpretado en el PS o alegórico. Dentro del primer grupo encontramos, en las obras dantianas, a Virgilio, Beatriz, san Bernardo, Catón y su mujer Marcia y tantos ejemplos bíblicos y profanos que en el Purgatorio, representan a las virtudes y los vicios. En el Paraíso Terrenal (Pg. XXVIIXXXIII) abundan las alegorías inventadas: desde la Prudencia, alegorizada por una dama con tres ojos, uno en la nuca; el carro jalado por un grifo; hasta Matelda. Esta magnífica dama es quizá la alegoría dantiana donde la figura y lo figurado — nuestros dos planos — se unen en la más íntima simbiosis. Su belleza, sus gestos, sus acciones, sus palabras sólo tienen sentido por lo que alegorizan y por el sitio alegórico donde se desarrollan.

Prudencio, Marciano Capela y Boecio fueron los principales alegoristas cristianos antes de la Edad Media. Los sentimientos, las virtudes, los vicios, las ciencias se concretaron, a partir de estos escritores, en una mujer con determinadas características alusivas. La literatura española no estuvo ajena a esta corriente. Léase De la pelea que ovo don Carnal con la Quaresma del Arcipreste de Hita o las Coplas de los pecados mortales de Juan de Mena.

Por declaración explícita de Dante, toda la Comedia es una alegoría: En cuanto a la materia de este libro, hay que verla según la letra y, luego, según la interpretación alegórica. El sujeto de toda la obra, tomada sólo literalmente, es el estado de las almas después de la muerte, entendido genéricamente. En efecto, el proceso de toda la obra versa sobre él y en torno de él. Pero si se toma la obra alegóricamente el sujeto es el hombre, que, según sus méritos o deméritos por su libre arbitrio, se somete a la justicia con premio o castigo (Epistola a Can Grande della Scala, 24-25). Lo interesante de esta frase es la obligación que se impone al lector de leerla alegóricamente. Pero, aunque toda la Comedia sea alegórica, no todo en ella es alegórico. Lo histórico adquiere muy a menudo valor propio per se. La Comedia no es como el Roman de la Rose con su abrumador alegorismo. El PJ es el viaje de Dante personaje, guiado, no simplemente acompañado, por Virgilio, Matelda, Beatriz y san Bernardo a través del Infierno, Purgatorio, Paraíso Terrenal y Paraíso propiamente 
dicho. ${ }^{2}$ Notemos que el Paraíso Terrenal tiene un PJ totalmente inventado como lugar escatológico. El PS de la Comedia es didáctico: cómo llegar a l'ultima salute a través de las vidas activa y contemplativa. Dante personaje asume la alegoría de la humanidad y las cuatro personas citadas, la de las dos vidas. Dante nos indica también esta exigencia, como lo veremos.

Fácil sería citar las fuentes de esta doctrina de las dos vidas: empezando por Platón y Aristóteles, continuando con Orígenes, san Agustín, san Gregorio, y acabando con Ricardo de san Víctor, Pedro Lombardo y santo Tomás de Aquino (S.T. 2-2, q.179-182). Pero más práctico es recurrir al mismo Dante para conocer qué valor alegórico otorgaba al Paraíso Terrenal y cuáles eran sus ideas personales sobre las vidas activa y contemplativa:

La inefable Providencia ha puesto al hombre dos fines a que tender, es decir, la felicidad en esta vida, que consiste en la actuación de la propia virtud (o fuerza, uirtus) y que es figurada por el Paraíso Terrenal; y la felicidad de la vida eterna, que consiste en el goce de la visión de Dios a la que la propia virtud solo puede subir con la ayuda de la luz divina, y que se da a entender por el Paraíso Celestial. A estas felicidades, como a diversos fines, hay que llegar por diversos medios. En efecto, llegamos a la primera por medio de las enseñanzas filosóficas, con tal que las sigamos obrando según las virtudes morales e intelectuales. A la segunda, por medio de las enseñanzas divinas, que trascienden la razón humana, con tal que las sigamos obrando según las virtudes teologales, es decir, la Fe, la Esperanza y la Caridad (Mn., III, XVI).

2 Más exacto es decir que los verdaderos guías son Virgilio y Beatriz. Matelda se mueve dentro del Paraíso Terrenal y san Bernardo permanece extático y estático frente a todo el Empíreo y a la Virgen, y guía a Dante solo con los ojos y la palabra. En Pd. XXXII, 115-116 le dice: vieni omai con li occhi sì com’̈o / andrò parlando. 
El Papa debería guiar a los hombres hacia la vida eterna (vida contemplativa), y el emperador conducirlos hacia la felicidad temporal (vida activa).

Íntimamente ligada a la doctrina de las dos felicidades, terrenal y celestial, en Dante aparece la doctrina de las vidas activa y contemplativa. Precisamente en Cv., IV, XVII, al acabar de enumerar las virtudes morales, dice que podemos tener en esta vida dos felicidades según dos diversos caminos, bueno uno, y óptimo el otro, que a ellas conducen: uno es la vida activa y el otro es la contemplativa. Resumamos. La vida activa es la actuación de la propia virtud, mediante las enseñanzas filosóficas y la práctica de las virtudes humanas. Con la gracia divina adquiere su perfección. La vida contemplativa añade a la anterior las enseñanzas divinas y la práctica de las virtudes teologales, que nos preparan a la visión beatífica.

En Pg. XXVII, Dante ya ha pasado por todos los andenes de la montaña del Purgatorio y está en la escalera que sube a la meseta superior, donde se sitúa el Paraíso Terrenal. Aquí pasa la noche dormido y le sobreviene el tercer sueño alegórico-profético en la montaña. Dante ve en el sueño a Lía, quien, al presentarse, establece en bellísimos versos el siguiente paralelo con su hermana Raquel:

Lía

con mis bellas manos siempre activas voy cogiendo flores en torno para hacerme una guirnalda

me adorno para mirar y contemplarme ante el espejo

deseosa estoy de adornarme con las manos

me satisfago en la acción

\author{
Raquel \\ sin cesar está sentada delante \\ de su espejo (Dios)
}

no separa nunca la vista de

Dios

deseosa está de contemplar

con sus bellos ojos

se satisface en contemplar a

Dios. 
El uso de Lía y Raquel para alegorizar las vidas activa y contemplativa está consagrado por la tradición. Leer el Contra Faustum Manicheum, L. 22, y el De consensu Euangelistarum, I,5,8 de san Agustín, así como los Homiliarum in Ezechielem libri, II, II, 7-13 de san Gregorio.

Lía y Raquel, pues, prefiguran a las dos mujeres con igual alegoría, que van a aparecer en el Paraíso Terrenal: Matelda y Beatriz. Estamos, en efecto, ante dos alegorías dobles con un común PS, las vidas activa y contemplativa, o sea, en definitiva, también la Gracia:

$\begin{array}{ccc}\text { PJ1 } & \text { PS } & \text { PJ2 } \\ \text { Lía } & \text { Vida activa } & \text { Matelda } \\ \text { Raquel } & \text { Vida contemplativa } & \text { Beatriz }\end{array}$

Matelda y Beatriz son guías de Dante en el más allá, pero no las únicas, ni las primeras ni las últimas. Virgilio conduce a Dante durante 61 cantos, en el Infierno y en el Purgatorio. San Bernardo es el personaje que presenta a Dante ante la Virgen para prepararlo a la visión beatífica. Así tenemos que la vida activa es alegorizada, primero, por Virgilio, y perfeccionada por Matelda. Lo mismo sucede con la vida contemplativa, que, alegorizada por Beatriz, es perfeccionada por san Bernardo. A esta conclusión se llega no sólo a través de la lógica y coherencia del poema, sino también y principalmente con las expresas indicaciones de Dante.

Repasemos las últimas palabras de Virgilio, dichas precisamente antes del ingreso en el Paraíso Terrenal y que representan el fin de su papel de conductor:

\author{
Il temporal foco e l'etterno \\ veduto hai, figlio; e se' venuto in parte \\ dov'io per me più oltre non discerno.
}

Tratto tho qui con ingegno e con arte; 
lo tuo piacere omai prendi per duce;

fuor se' de l'erte vie, fuor se' de l'arte [...].

Non aspettar mio dir più né mio cenno,

libero, dritto e sano è tuo arbitrio,

e fallo fora non fare a tuo cenno:

per chio te sovra te corono e mitrio.

(Pg. XXVII, 127-132; 139-140) $)^{3}$

Virgilio explica que él solo, como alegoría de la vida activa o del perfeccionamiento de la vida humana, mas sin cristianizarse, es decir, sin las virtudes teologales y la gracia, «no discierne más allá». La cristianización de Dante personaje — la humanidad — se realizará con Matelda en el Paraíso Terrenal, lugar donde todo, incluyendo el mismo sitio, es alegórico.

Virgilio desde su aparición se presenta como enviado por Dios. ¿Hemos notado cuántas veces se repite el verbo «mover» en If. II? María, mediadora de la Gracia, «mueve» (v.101) a Lucía, la cual «mueve» (v. 72) a Beatriz para que esta «mueva» (v. 67) a su vez el inicio de la función de Virgilio (perfección humana), cuyo «movimiento» (v. 141) Dante sigue. Los teólogos siempre han considerado a la Gracia como una motio.

Convencido de la función de Virgilio, Dante exclama entusiasmado:

Or va', ch'un sol volere è d'ambedue:

tu duca, tu segnore, e tu maestro

(If. II, 139-140) ${ }^{4}$

3 «Hijo, has visto el fuego y las penas temporales del Purgatorio y las del Infierno, y has llegado a este lugar del Paraíso Terrenal donde yo con solo mi razón no discierno más allá de cuanto te he enseñado. Te he conducido hasta aquí con la inteligencia y con la aplicación práctica; ahora hazte guiar por tu espontánea libertad; ya estás fuera de toda dificultad, tanto en los caminos escarpados como en los estrechos... Ya no esperes más mis palabras ni mis gestos. Ya, libre, tu arbitrio está recto y sano en el bien, y sería error no secundarlo: por esto pongo sobre tu cabeza la corona de señor y la mitra de pastor de ti mismo».

4 «Precédeme, pues, porque ambos ya queremos una sola cosa, y desde ahora serás el guía de mis pasos, el árbitro de mi voluntad, el maestro de mi intelecto.» 
La residencia habitual de Virgilio es el nobile castello, en el Limbo, que es el primer círculo del Infierno. Homero, acompañado por Horacio, Ovidio y Lucano, lo recibe con estas palabras:

\author{
Onorate l'altissimo poeta: \\ l'ombra sua torna, ch'era dipartita \\ (If., IV, 80-81)
}

En el Paraíso Terrenal, apenas Beatriz aparece, Virgilio desaparece para regresar al nobile castello o limbo. Dante al ver a su amada trasfigurada, se voltea para compartir con él su gozo,

\author{
Ma Virgilio n'avea lasciati scemi \\ di sé, Virgilio dolcissimo patre, \\ Virgilio a cui per mia salute die' mi; \\ né quantunque perdeo l'antica matre, \\ valse a le guance nette di rugiada \\ che, lagrimando, non tornasser atre
}

(Pg. XXX, 49-54)

Versos conmovedores que nos provocan preguntar: ¿por qué Dante autor no salvó excepcionalmente a Virgilio así como lo hizo con Catón, Trajano y hasta con el oscuro personaje de la Eneida, Rifeo? Muchos pasajes de la Comedia sólo se entienden a la luz de la alegoría. La irreverencia de la espantosa vieja de Pd. XI solo se salva si tomamos en cuenta su significado alegórico, la Pobreza: dove Maria rimase giuso,/ ella con Cristo pianse in su

5 «iHonrad al excelso poeta! Su espíritu, que había partido, regresa a nosotros.» 6 «Pero Virgilio nos había privado de él, Virgilio, el dulcísimo padre; Virgilio a quien me había entregado para ser salvado; todas las bellezas del Paraíso Terrenal, que perdió nuestra antigua madre Eva, no pudieron impedir que mis mejillas, ya limpias con el rocío, se afearan por el llanto.» 
la croce (Pd.XI, 71-72): 'mientras María Santísima permaneció a los pies de la cruz, ella subió a la cruz y lloró con Cristo desnudo y crucificado'. La magnanimidad de Ulises es condenada en If. XXVI com'altrui piacque, no por capricho divino sino porque el gran griego se esforzó inútilmente por salvarse - o por llegar a la montaña del Purgatorio- con sus solas fuerzas, sin Dios. Verdaderamente su viaje fue un folle volo ('un loco vuelo') pelagiano. Para los cristianos, y Dante lo era en sumo grado, el alma se salva per sola grazia, non per esser degna (Pd. XII, 42): 'solo por gracia divina y no por ser digna y meritoria'. Virgilio mismo declara en Pg. XXII, 60: la fede, sanza qual ben far non basta: 'la fe, sin la cual para salvarse no basta hacer el bien'.

Virgilio, pues, regresa al Limbo únicamente por el significado alegórico esquemático que le otorgó Dante autor: vida activa sin participación divina. Virgilio está muy consciente de ello: quello imperador che là su regna [...] non vuol chèn sua città per me si vegna (If., I, 124. 126). Y así se presenta a Sordello:

\author{
Io son Virgilio; e per null'altro rio \\ lo ciel perdei che per non aver fé
}

(Pg.VII, 7-8)

¿Qué piensan los dantólogos sobre el valor alegórico de Virgilio? Aquí es cuando se verifica el dicho de san Agustín: Grandius aenigma, ut non uideamus quod non uidere non possumus. Unos no se detienen en ninguna alegoría por considerarla antipoética, como Croce y secuaces. Otros ven en Virgilio un símbolo de Dante mismo, la idea imperial o gibelina, el vehículo del amor divino, la libertad... Hay quienes se acercan parcialmente a la intención de Dante: la razón humana sometida a la trascendencia preparando la llegada de la revelación, la ciencia humana, el Estudio y el Amor (Pascoli),

7 «Yo soy Virgilio y perdí el cielo por ninguna otra culpa que no tener fe.» 
la sabiduría pagana, la filosofía, la razón y el arte o, con mayor perífrasis, «la alianza entre poesía y verdad por medio del amor a las cosas»...

A Dante hay que interpretarlo con Dante mismo. En sus obras hay poco margen a la adivinación. Salvo en los enigmas, que por definición son oscuros, Dante mismo nos da la clave de casi todas sus alegorías. Basta leerlo con inteligencia, atención y memoria.

La asociación de Virgilio con Matelda para significar la vida activa es muy clara. Leamos con atención la siguiente frase de Virgilio:

\author{
Quanto ragion qui vede \\ dir ti possio; da indi in là t'aspetta \\ pur a Beatrice, chè opra di fede \\ (Pg. XVIII, 46-48) ${ }^{8}$
}

Virgilio, como alegoría de la primera fase de la vida activa (actuación de la propia virtud mediante las enseñanzas filosóficas y la práctica de las virtudes humanas), necesita a Matelda (la gracia divina) para cumplir su elevada función, que es, nada menos, representar al hombre perfecto recién salido de las manos de Dios en el Paraíso Terrenal. Virgilio, pues, puede omitir en este párrafo a Matelda (a quien, por otra parte, aún no conoce) al compararse con Beatriz, la vida contemplativa, que consiste en la actuación de las virtudes teologales. Beatriz y san Bernardo —opra di fede — elevarán a la razón humana, es decir, a Virgilio y Matelda.

Al lado de estas palabras y acciones que delatan la alegoría de Virgilio, muchos otros datos proporcionados en la Comedia son de estricto valor histórico. Tales son las primeras palabras de Virgilio al presentarse

8 «Acerca de este problema te puedo decir todo lo que comprende la razón humana natural; más allá de estos límites pon tu expectativa solo en Beatriz, porque la materia es de competencia de la fe.» 
a Dante (If. I, 67-68): nació en época de César, vivió durante Augusto, escribió la Eneida. Entonces Dante exclama:

\author{
Or se' tu Virgilio e quella fonte \\ che spandi di parlar sì largo fiume? [...] \\ $O$ delli altri poeti onore e lume, \\ vagliami 'l lungo studio e 'I grande amore \\ che m'ha fatto cercar lo tuo volume. \\ Tu se' lo mio maestro e 'l mio autore; \\ tu se' solo colui da cu' io tolsi \\ lo bello stilo che m'ha fatto onore
}

(If. I, 79-87) ${ }^{9}$

Virgilio es el famoso saggio (If. I, 89), el mar di tutto 'l senno (If. VIII, 7), el dottore (If. V, 70), la gloria di Latin... per cui mostrò ciò che potea la lingua nostra (Pg. VII, 16-17): 'la gloria de todos los italianos, por quien nuestra lengua demostró toda su potencia artística'; lo maggiore nostro poeta (Cv. IV, XXVI, 8), nostra maggior Musa (Pd. XV, 26), el anima cortese mantoana de la parola ornata, del parlare honesto, etc.

Gran mérito de Dante ha sido que su Virgilio histórico se nos presente tan libre de las deformaciones que la Edad Media le infligió. Domenico Comparetti en su Virgilio nel Medio Evo y las observaciones de Giorgio Pasquali han profundizado muy bien en la materia. Sólo tres pasajes en la Comedia parecen aludir a las leyendas sobre Virgilio como mago o nigromante.

$9 \quad$ «Entonces tú eres el famoso Virgilio, la fuente de la que fluye el gran río de la elocuencia? ¡Oh decoro y luz de los otros poetas, me valga contigo el largo estudio y el gran amor que me impulsó a buscar tus libros! Tú eres mi maestro y mi autor preferido. Solo de ti aprendí el bello estilo que me ha dado la fama.» 
En el canto IX del Infierno, como delante de la puerta de Dite ambos poetas encuentran la oposición de los diablos, Virgilio reanima a Dante con estas palabras:

\author{
Di rado \\ incontra [...] che di nui \\ faccia 'l cammino alcun per qual io vado \\ Vero è ch'altra fiata qua giù fui, \\ congiurato da quella Eritòn cruda \\ che richiamava l'ombre a' corpi sui. \\ Di poco era di me la carne nuda, \\ chella mi fece intrar dentr'a quel muro, \\ per trarne un spirto del cerchio di Giuda
}

(If. IX, 19-27) ${ }^{10}$

El origen de esta leyenda se encuentra en el truculento pasaje de la Farsalia (VI, 506-830) de Lucano. Allí Sexto Pompeyo ruega a la maga tesalia Ericto que evoque al espíritu de un soldado muerto para saber el resultado de la batalla de Farsalo. Dante, quizá interpretando mal el uatem del verso 628 de la obra, supone, en boca de Virgilio, que este fue el conjurado. Dejando de lado los errores cronológicos, me parece que esta invención dantiana sirve para dar mayor dramaticidad al impedimento diabólico para entrar en la ciudad de Dite. Como Virgilio habría bajado antes de Cristo, entonces no habría existido aún el círculo VI, de los herejes, y la ciudad de Dite no habría estado tan protegida. De ahí el terror de Dante (VIII, 94 ss.) y el disgusto

\footnotetext{
10 «Raramente sucede que alguien de nosotros haga el viaje que estoy haciendo contigo. Pero tranquilízate porque otra vez ya estuve aquí abajo, conjurado por la cruel Ericto, que evocaba las sombras a sus cuerpos con encantos. Hacía poco que mi cuerpo estaba privado de mi espíritu, cuando me hizo penetrar adentro de estos muros de Dite para sacar a un espíritu del círculo de Judas, el último.»
} 
(v.118 ss.) y el palidecer de Virgilio (IX, 1). Además la posterior creación del círculo de los herejes explicaría también su peculiar ubicación, que rompe el esquema moral aristotélico por estar entre los pecadores de incontinencia y los pecadores por malicia. De todos modos Virgilio, en la Comedia, se presenta como objeto de una operación mágica, no como mago. En If. XII, 34-35 se vuelve a tocar el episodio, pues Virgilio encuentra derruido el puente sobre el VI «jirón» a causa del terremoto que ocasionó la «bajada» de Cristo a los Infierno. Este accidente también da lugar a la dramática travesía en bote del Flegetonte, el río de sangre de los violentos. En If. XXI, 61-63, Virgilio informa a Dante que otrora ya había entablado trato con la banda de diablejos que pueblan la «bolsa» de los coimeros.

En el Purgatorio, nuestros dos poetas se encuentran con otro, que es Estacio, de quien ahora sabemos que fue napolitano y pagano. Los medievales, empero, lo confundieron con un retórico homónimo tolosano de la época de Nerón. Además se contaba que la lectura de la IV Bucólica virgiliana produjo su conversión al cristianismo. Dante creyó en todo ello por lo que tenemos a Estacio como acompañante durante una docena de cantos en el Purgatorio. La leyenda concierne más a Estacio que a Virgilio, mas es útil leer el emocionante y tierno encuentro. Sin reconocerse aún, el autor de la Tebaida cuenta su vida y obras:

Al mio ardor fuor seme le faville, che mi scaldar, della divina fiamma onde sono allumati più di mille;

dell'Eneïda dico, la qual mamma

fummi e fummi nutrice poetando:

sanz'essa non fermai peso di dramma.

E per esser vivuto di là quando

visse Virgilio, assentirei un sole

più che non deggio al mio uscir di bando

(Pg. XXI, 94-102) ${ }^{11}$

11 «Mi férvido canto se encendió por las chispas, que siempre me calentaron, de aquella llama poética con la que se iluminaron muchísimos poetas; hablo de la llama 
Dante mira sonriendo de reojo a Virgilio. Estacio intrigado, le pregunta por qué se sonríe, y Dante le revela que está frente a Virgilio. Estacio entonces se echa a los pies de Virgilio para abrazarlos y este le hace ver que ambos son espíritu, es decir, inasibles. Estacio se levanta y exclama:

\author{
Or puoi la quantitate \\ comprender dell'amor ch'a te mi scalda, \\ quand'io dismento nostra vanitate, \\ trattando l'ombre come cosa salda \\ (Pg. XXI, 133-136) $)^{12}$
}

Esta escena es una de las más graciosas e intimistas de la Comedia. Cae a la perfección en el Purgatorio, donde se celebra de diversas maneras la amistad. En el siguiente canto, Virgilio pregunta a Estacio cómo se convirtió al cristianismo, y recibe como respuesta los siguientes alados versos:

\author{
Tu prima minvïasti \\ verso Parnaso a ber nelle sue grotte, \\ e prima appresso Dio malluminasti. \\ Facesti come quei che va di notte, \\ che porta il lume dietro e sé non giova, \\ ma dopo sé fa le persone dotte, \\ quando dicesti: "Secol si rinova; \\ torna giustizia e primo tempo umano,
}

de la Eneida, que mientras poetizaba me fue madre, encendiéndome mi amor a la poesía y me fue nutriz educándolo: sin su ejemplo no grabé nada en mis cantos, incluso los de menor valor. Y si fuese posible haber vivido en la tierra en tiempos de Virgilio, aceptaría permanecer todavía aquí, lejos del Paraíso, un año más de lo que debería.»

12 «Ahora puedes entender cuán grande es el amor que me inflama por ti, ya que olvido que somos incorpóreos y trato a las sombras como cuerpos sólidos.» 
e progenie scende da ciel nova".

Per te poeta fui, per te cristiano.

(Pg. XXII, 64-73) ${ }^{13}$

Estacio no sólo declara que la lectura de la IV bucólica lo hizo cristiano, sino también con sus palabras aclara la función alegórica de Virgilio: la primera fase de la cristianización del hombre, su perfección humana a través de la vida activa. Su presencia en el Purgatorio depende totalmente de Virgilio. Es inútil buscarle alegoría: sólo vale como personaje «histórico».

Dante fue quizá el poeta que mejor entendió la religiosidad de la Eneida. Es indudable que de ella brotó la idea de escribir la Comedia, pero también la de hacer un poema sacro al quale ha posto mano e cielo e terra (Pd. XXV, 1-2). Ya Macrobio había llamado sacrum poema a la Eneida (Sat., I, 24, $13)$.

La influencia de Virgilio sobre Dante es tan grande que se requeriría un libro para describirla. Basta decir ahora que hasta en la estructura de la Comedia se nota la influencia virgiliana. El L.VIII de la Eneida es sin duda el pináculo de toda su obra. Está situado en la sección del número áureo (1 y 0,618$)$ y desarrolla un episodio recapitulador y explicativo de todos los sucesos pasados y futuros de la epopeya. El episodio del Paraíso Terrenal, también situado en la sección áurea de la Comedia, cumple la misma función. Ambos libros, la Eneida y la Comedia, parecerían incompletos sin el L.VIII en el primer caso y sin los cánticos 28-33 del Purgatorio en el segundo. En estos se aclara completamente el sentido de la vida activa (alegorizada por

13 «Tú primero me hiciste poeta cuando me acercaste al Parnaso para beber en la fuente de Castalia, que brota de sus rocas, y tú primero me diste luz ante Dios para verlo y luego conocerlo por la fe. Haz hecho como quien camina de noche, que lleva la luz atrás y de ella no se beneficia, pero hace expertos del camino a las personas que lo siguen, cuando dijiste: «El siglo se renueva, regresan la justicia y la primera edad de oro, la edad de la humanidad inocente, y del cielo desciende una nueva progenie». Por ti me hice poeta, por ti cristiano.» 
Virgilio y Matelda), ya cumplida, y el de la vida contemplativa (alegorizada por Beatriz y san Bernardo), que está a punto de desarrollarse. ${ }^{14}$

Al final de la Vita Nuova (XLII) Dante promete que, si la mia vita duri per alquanti anni, io spero di dicer di lei [de Beatriz] quello che mai non fue detto d'alcuna ('si mi vida dura por algunos años más, espero decir de Beatriz lo que jamás se dijo de mujer alguna'). El nombre de Beatriz (la «beatificadora») era ya todo un programa, y el elevarla a la función de la vida contemplativa fue en verdad algo que nunca se dijo de una mujer. Virgilio al mismo tiempo fue elevado al rango de alegoría de la vida activa. Dante cumplió sobradamente su promesa: nunca personas humanas fueron elevadas tanto por la alegoría.

14 Recomiendo nuevamente la lectura de la introducción a nuestra traducción de la Eneida y el artículo Matelda: alegoría y enigma (1984-1985). 


\section{BIBLIOGRAFÍA}

AA. VV.

1970 Enciclopedia Dantesca. 6 tomos. Roma: Istituto della Enciclopedia Italiana.

Auerbach, E.

1977

Studi su Dante. Milán: Feltrinelli Economica.

Contini, G.

$1970 \quad$ Unidea di Dante. Turín: Piccola Biblioteca Einaudi.

Dante Alighieri

1922 La Divina Commedia. Commento e parafrasi di Carlo Dragone. Milán: Edizioni Paoline.

1960 La Divina Commedia. A cura di Daniele Mattalìa. Milán: Rizzoli Editore.

1960 Opere Minori. A cura di Alberto del Monte. Milán: Rizzoli Editore.

1988 La Divina Commedia. A cura di U. Bosco e G. Regio. Florencia: Le Monnier.

Hollander, R.

1969 Allegory in Dante’s Commedia. Princeton: University Press.

LAUSBERG, H.

1966

Manual de Retórica Clásica. Madrid: Gredos.

Madaule, J.

1957 Dante et la rigueur italienne. Bruselas: Éditions Complexe. 
Petrocchi, G.

1987 L'Inferno di Dante. Milán: Biblioteca Universale Rizzoli.

1987 Il Purgatorio di Dante. Milán: B.U.R.

PicASSO, J.

1984-1985 «Matelda: Alegoría y Enigma (Dante, Comedia, Pg., XXVIIXXXIII)». Boletín del InstitutoRiva Agüero. Lima.

1988 "La Virgen María en la Comedia de Dante». RTL, n. ${ }^{\circ} 1$. Lima.

1989 «El tres y el círculo (Ensayo dantiano)». RTL, n.o 3. Lima.

1997 «Dante y la leyenda de Silvestre y Constantino». Boletín del InstitutoRiva Agüero. Lima.

RISSET, J.

1982 Dante écrivain ou l'intelletto d'amore. París: Seuil.

Singleton, Ch.

1978 La poesía della Divina Commedia. Boloña: il Mulino.

VIRGILIO

2004

Bucólicas y Geórgicas. Trad. de Julio Picasso M. Lima: Fondo Editorial UCSS.

2007 Eneida. Trad. de Julio Picasso M. Lima: Fondo Editorial UCSS. 